\title{
Characterization of the distributions of collagen and PGs content in the decellularized book-shaped enthesis scaffolds by SR-FTIR
}

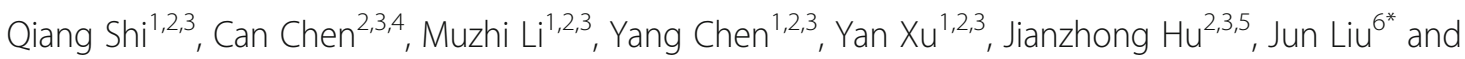
Hongbin Lu $\mathrm{L}^{1,2,3}$

\begin{abstract}
Background: Bone-tendon interface (enthesis) plays a pivotal role in relaxing load transfer between otherwise structurally and functionally distinct tissue types. Currently, decellularized extracellular matrix (DEM) from enthesis provide a natural three-dimensional scaffold with tissue-specific orientations of extracellular matrix molecules for enthesis regeneration, however, the distributions of collagen and PGs content in the decellularized book-shaped enthesis scaffolds from rabbit rotator cuff by SR-FTIR have not been reported.

Methods: Native enthesis tissues (NET) harvested from rabbit rotator cuff were sectioned into cuboid (about 30 $\mathrm{mm} \times 1.2 \mathrm{~mm} \times 10 \mathrm{~mm}$ ) for decalcification. The decellularized book-shaped enthesis scaffolds and intrinsic ultrastructure were evaluated by histological staining and scanning electron microscopy (SEM), respectively. The distributions of collagen and PGs content in the decellularized book-shaped enthesis scaffolds from rabbit rotator cuff were also measured innovatively by SR-FTIR.

Results: The decellularized book-shaped enthesis scaffolds from rabbit rotator cuff were successfully obtained. Histomorphology and SEM evaluated the effect of decellularization and the structure of extracellular matrix during decellularization. After mechanical testing, the failure load in the NET group showed significantly higher than that in the DEM group $(P<0.05)$. Meanwhile, the stiffness of the DEM group was significantly lower than the NET group. Furthermore, the distributions of collagen and PGs content in the decellularized book-shaped enthesis scaffolds were decreased obviously after decellularization by SR-FTIR quantitative analysis.

Conclusion: SR-FTIR was applied innovatively to characterize the histological morphology of native enthesis tissues from rabbit rotator cuff. Moreover, this technology can be applied for quantitative mapping of the distribution of collagen and PGs content in the decellularized book-shaped enthesis scaffolds.
\end{abstract}

Keywords: SR-FTIR, Decellularized book-shaped enthesis scaffolds, Bone-tendon interface, Rabbit rotator cuff

\footnotetext{
*Correspondence: liujunheliyun@163.com

${ }^{6}$ Department of limbs (foot and hand) microsurgery, Affiliated Chenzhou

No.1 People's Hospital, Southern Medical University, Chenzhou 423000,

Hunan, China

Full list of author information is available at the end of the article
}

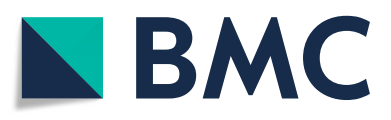

(c) The Author(s). 2021 Open Access This article is licensed under a Creative Commons Attribution 4.0 International License, which permits use, sharing, adaptation, distribution and reproduction in any medium or format, as long as you give appropriate credit to the original author(s) and the source, provide a link to the Creative Commons licence, and indicate if changes were made. The images or other third party material in this article are included in the article's Creative Commons licence, unless indicated otherwise in a credit line to the material. If material is not included in the article's Creative Commons licence and your intended use is not permitted by statutory regulation or exceeds the permitted use, you will need to obtain permission directly from the copyright holder. To view a copy of this licence, visit http://creativecommons.org/licenses/by/4.0/ The Creative Commons Public Domain Dedication waiver (http://creativecommons.org/publicdomain/zero/1.0/) applies to the data made available in this article, unless otherwise stated in a credit line to the data. 


\section{Background}

Bone-tendon interface (BTI), which is also named as enthesis, serves as an interface for force transmission from bone to tendon that consists of four transitional tissues: tendon, uncalcified fibrocartilage, calcified fibrocartilage, and bone [1, 2]. This transitional enthesis allows smooth transmission of forces derived from muscle contraction and minimizes formation of stress peaks [3, 4]. Enthesis injury, particularly those in the rotator cuff, are prevalent conditions that often lead to disability and persistent pain [5]. Regrettably, rapid and functional enthesis regeneration remains difficult because of its poor capacity of self-repair during healing [6-8]. Thus, conventional surgical treatment, only attaching the ruptured tendon and bony footprint together, cannot recapitulate the enthesis with graded and transitional structure, thus resulting in a high rate of re-rupture (20-94\%) [1, 9].

With the development of tissue engineering technology, decellularized bioscaffolds have received great attention [10-12]. Previous studies indicated that organ-specific extracellular matrix scaffolds derived from site-specific homologous tissues may be better suited for constructive tissue remodeling than no site-specific tissue sources. As a result, decellularized extracellular matrix from enthesis may provide a natural three-dimensional scaffold with tissue-specific orientations of extracellular matrix molecules for enthesis regeneration. However, previously developed protocols for single tissue decellularization cannot be combined to prepare the decellularized enthesis scaffolds, as different tissues exhibit large differences in their components, microstructure characteristics and durability. Besides, the fibrocartilage region of enthesis is dense with low porosity, allowing for limited acellular solution infiltration, it is technically hard to remove its cellular components and antigens while mostly conserving native ECM. Thus, in this study, bone was treated together with fibrocartilage and tendons with different solutions in the same composite.

Histologically, BTI exhibits a gradual increase in collagen fiber organization moving from the bone to tendon [13]. The abundant type I collagen molecules are supplemented with type II, IX and XI collagen, and increased amount of proteoglycans is characteristic [14]. To date, Raman spectroscopy and Fourier transform infrared spectroscopic imaging (FTIR-I) have been used to analyze complex tissue transitions such as the ligament-to-bone [15] and tendon-to-bone [16, 17] interfaces. Recently, synchrotron radiation-based fourier transform infrared microspectroscopy (SR-FTIR) has been proved to be a useful tool for the analysis of biochemical quantification of collagen and proteoglycan content in biological samples [18]. In our previous studies, the SRFTIR technology for quantitative mapping of the content and distribution of extracellular matrix in book-shaped decellularized fibrocartilage scaffold has been reported [19]. Zhou et al. found that SR-FTIR could be applied for quantitative evaluation of collagen and GAG in the cellularized or decellularized bioscaffolds [20]. The surgical outcome in small-animal experiments, such as mice, may not be replicable in large animals owing to differences in joint anatomy (structure) and function (mechanics) [3]. Furthermore, the healing ability of small animals is often faster than that of large animals or humans. Hence, the rabbit models of BTI healing that mimics the mechanical loading and healing ability of humans to evaluate a variety of new strategies for the treatment of rotator cuff tears is desirable [21]. Additionally, Mathewson et al. [22] compared rotator cuff muscle architecture of several animal models with that of humans and demonstrated that rabbit muscular parameters were more similar to humans than that in other large animals. However, to date, the application of SR-FTIR for quantitative evaluation of collagen and GAG in decellularized book-shaped enthesis scaffolds from rabbit rotator cuff has not been reported.

In this study, SR-FTIR was applied for quantitative mapping of the content and distribution of extracellular matrix in the decellularized book-shaped enthesis scaffolds from rabbit rotator cuff and verifying the decellularized method conducted by $\mathrm{Su} \mathrm{M}$ et al' protocol which could shorten decellularized time, well preserve the native structure, extracellular matrix components and mechanical properties of enthesis tissue [23].

\section{Methods \\ Preparation of book-shaped bone-fibrocartilage-tendon samples}

The whole experiment design is overviewed as in Fig. 1. The Ethics Committee of Xiangya Hospital, Central South University approved the research proposal (IRB: 2019030517). A total of 72 female New Zealand rabbits weighing $3.1 \pm 0.3 \mathrm{~kg}$ were used in this study. After they were euthanized (intraperitoneal injection of sodium pentobarbital, $100 \mathrm{mg} / \mathrm{kg}$ ), we obtained the native enthesis tissues (NET) specimens from rotator cuff, which were then sectioned into cuboid (about $30 \mathrm{~mm} \times 1.2 \mathrm{~mm} \times 10$ $\mathrm{mm}$ ) for decalcified and vertically sliced at the boundary between fibrocartilage and tendon. The specimens were sectioned into book shape from the tendinous end to bony end along motility direction with layer thicknesses of $250 \mu \mathrm{m}$.

\section{Preparation of decellularized book-shaped enthesis scaffolds}

The decellularized book-shaped enthesis scaffolds were prepared as previously described by $\mathrm{Su} \mathrm{M}$ et al' protocol. Briefly, the samples were first immersed in liquid nitrogen for $2 \mathrm{~min}$ and then thawed in sterile PBS at $37^{\circ} \mathrm{C}$ for $10 \mathrm{~min}$, which was repeated five times. Then the samples 


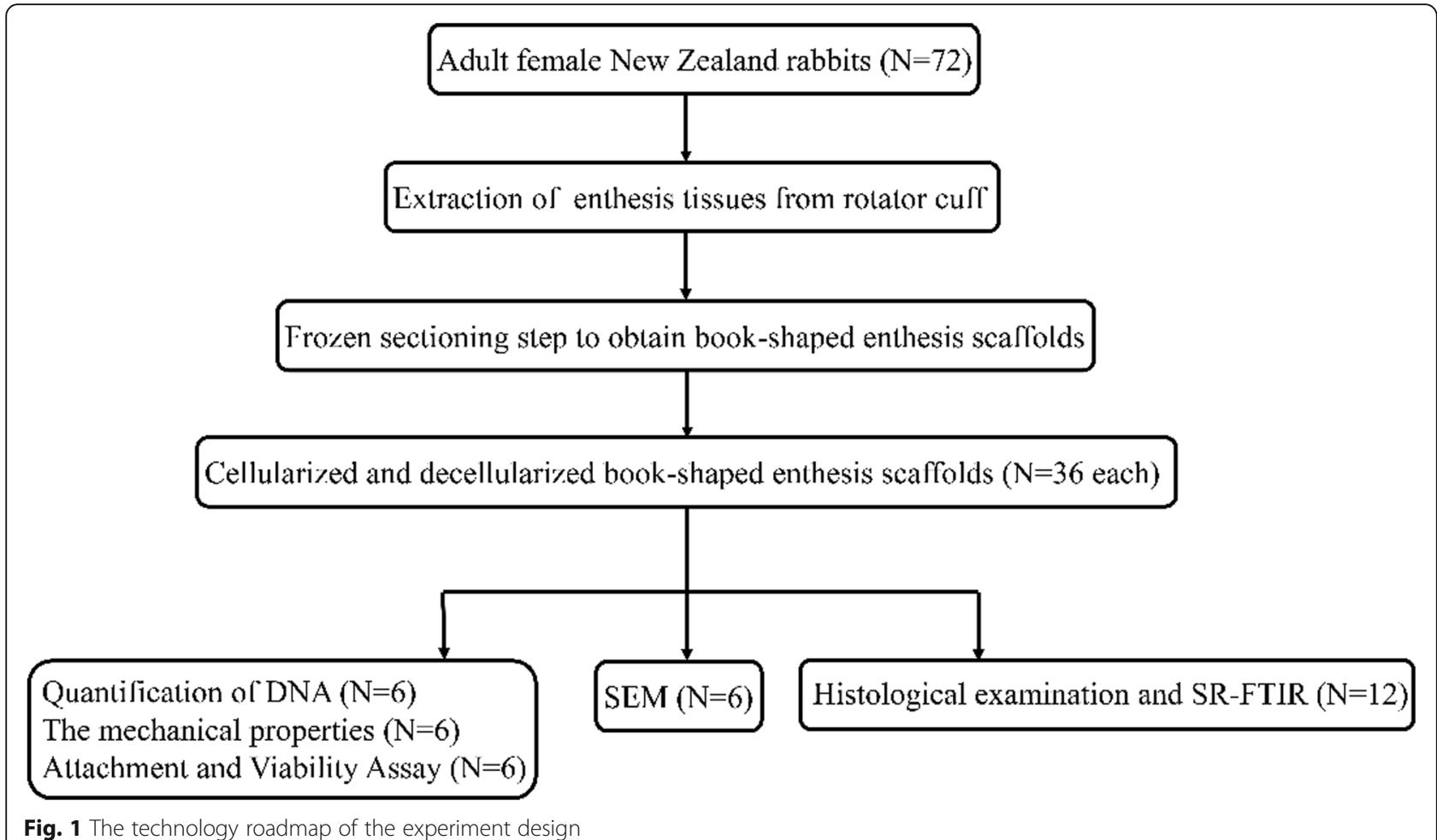

were soaked in 1\% Triton X-100 (Sigma-Aldrich, St. Louis, MO, USA) with agitation (100 rpm) for 1 day, followed by washing with $1 \%$ sodium dodecyl sulfate (SDS; Sigma-Aldrich) with agitation $(100 \mathrm{rpm})$ for 1 day and ultrapure water for 1 day. Next, the tendon part of the sample was placed in a custom-designed container. The bone and fibrocartilage were exposed to $2 \%$ Triton $\mathrm{X}-100$ for 4 days with agitation $(100 \mathrm{rpm})$ and then washed in ultrapure water for 1 day, followed by washing with 3\% SDS for 4 days with agitation (100 rpm) and ultrapure water for 1 day. Finally, the whole samples were treated with $100 \mathrm{U} \mathrm{mL}$ - 1 DNase I (Sigma-Aldrich) for $12 \mathrm{~h}$. Finally, the book-shaped enthesis scaffolds were washed with ultrapure water for 1 day and embedded in paraffin for histological, and SR-FTIR examinations.

\section{Histology and scanning electron microscopy (SEM) analysis}

Hematoxylin and eosin (H\&E), toluidine blue fast green and 4',6-diamidino-2-Phenylindole (DAPI) for histological observation was used to evaluate decellularized efficacy $(N=6)$. The decellularized book-shaped enthesis scaffolds from rabbit rotator cuff were embedded in paraffin and sectioned into $7 \mu \mathrm{m}$ slices, then stained with $\mathrm{HE}$, toluidine blue fast green and DAPI for observing the retention of nuclear materials. SEM image for the microstructure of the decellularized book-shaped enthesis scaffolds surface was observed and the decellularized components were detected $(N=6)$.

\section{SR-FTIR analysis}

In this present study, the synchrotron radiation-Fourier transform infrared spectroscopy (SR-FTIR) we innovatively applied to evaluate the preservation of collagen and PGs in the NET and DEM $(\mathrm{N}=6)$. The result of decellularization on the extracellular matrix components was evaluated using synchrotron radiation-Fourier transform infrared spectroscopy (SR-FTIR) at the BL01B beamline of National Facility for Protein Science Shanghai and Shanghai Synchrotron Radiation Facility, where synchrotron radiation from a bending magnet was collected, collimated and transported to a commercial FTIR interferometer bench. The peak area of amide I (1720-1590 cm-1) and carbohydrate $(1140-985 \mathrm{~cm}-1)$ in the infrared spectrum were respectively calculated to characterize the distribution and content of collagen and PGs of the NET or DEM. The specific procedures are as previously described according to the published literature [13].

\section{DNA content analysis and mechanical tests}

The quantifications of DNA in the decellularized bookshaped enthesis scaffolds were performed using DNeasy Blood \& Tissue protocol according to the manufacturer's instructions [12]. Specifically, the decellularized bookshaped enthesis scaffolds $(N=6)$ were weighed and minced after freeze-dried for $24 \mathrm{~h}$ using a lyophilizer (SIM International Group, USA). Then the decellularized bone-tendon scaffold $(10 \mathrm{mg})$ was digested with proteinase $\mathrm{K}$ at $56{ }^{\circ} \mathrm{C}$ for $3 \mathrm{~h}$. Finally, the DNA content 
in the decellularized book-shaped enthesis scaffolds was quantified by DNeasy Blood\&Tissue Kit (Qiagen, USA) together with PicoGreen DNA assay kit (Invitrogen, USA).

The mechanical properties of the NET and DEM were comparatively evaluated with mechanical testing system (MTS insight, MTS Systems Corp, USA) for failure testing. Each specimen was preloaded to $1 \mathrm{~N}$ and then loaded to failure at a rate of $20 \mathrm{~mm} / \mathrm{min}$. Failure load and stiffness were calculated from the load-displacement curve obtained from the testing.

\section{Attachment and viability assay}

After washing for three times with PBS $(3 \times 30 \mathrm{~min})$, the decellularized book-shaped enthesis scaffolds were sterilized and immersed in a complete medium overnight, then $10^{4}$ BMSCs were respectively seeded onto the decellularized book-shaped enthesis scaffolds. To evaluate the cytotoxicity of the decellularized book-shaped enthesis scaffolds on BMSCs, cell viability was evaluated with a Live/Dead Assay kit (Invitrogen) at day 3 after seeding, Live/Dead assay showed that the green- and red-stained cells were captured by fluorescence with excitation wavelength of $488 / 594 \mathrm{~nm}$ to quantify cell viability $(N=6)$.

\section{Statistical analysis}

The analyses were performed using the SPSS 25.0 software (SPSS, USA). All values were expressed as the mean \pm standard deviation. Statistical significance of the experimental variables was then evaluated using Student's t-test $(P<0.05$ was considered statistically significant).

\section{Results}

Characterization of the decellularized book-shaped enthesis scaffolds by macroscopic observation and histomorphology In this study, enthesis tissue was sectioned into "book" shape along motility direction with thickness of 250 um
(Fig. 2a). H\&E, Toluidine blue fast green, Dapi staining were used together to evaluate the decellularized effect. $H \& E$ and Toluidine blue fast green staining showed that the cellular components of the decellularized bookshaped enthesis scaffolds were absolutely removed, while the structure and morphology of the native enthesis extracellular matrix were well preserved (Fig. 2b, c). Besides, Dapi-positive cell nuclei were rarely shown in the decellularized book-shaped enthesis scaffolds (Fig. 2d).

\section{SEM analysis}

The surface topology of book-shaped enthesis scaffolds before or after decellularization was detected by SEM (Fig. 3). In the native book-shaped enthesis scaffolds, cells adhered to various native tissues. After decellularization, we observed no cellular components on the surface of the scaffold.

\section{Distribution and content of collagen and proteoglycan by SR-FTIR}

Collagen and proteoglycan contents were evaluated by integrating the peak area under the Amide I band $(1720-1590 \mathrm{~cm}-1)$ and $\mathrm{C}-\mathrm{O}-\mathrm{C}$ and $\mathrm{C}-\mathrm{OH}$ vibrations (1140-985 cm-1), respectively. In this study, we innovatively applied SR-FTIR to comparatively characterize the distribution and content of collagen and proteoglycan between NET and DEM. For each sample, regions of interest $(\sim 750 \times \sim 1750 \mathrm{um} / \mathrm{region})$ containing tendon, fibrocartilage, and bone were scanned, and $\sim 8000$ points of spectral data were acquired per region, constituting a total of $\sim 24,000$ spectra collected per sample. As presented in Fig. $4(N=6)$, the collagen content in the bone regions lost about 40.85\%, while the collagen contents in the CF (calcified fibrocartilage), UCF (uncalcified fibrocartilage) and tendon regions of DEM were similar without significant difference between NET and

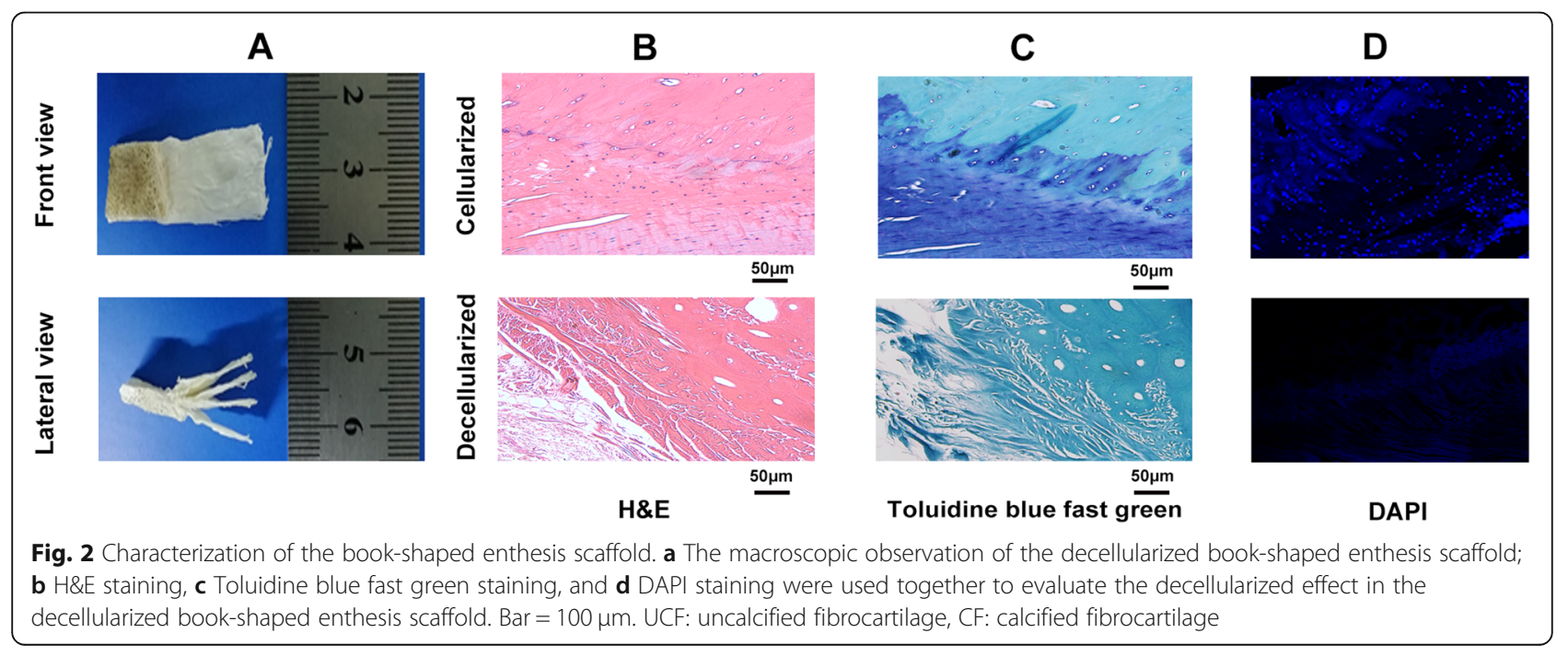




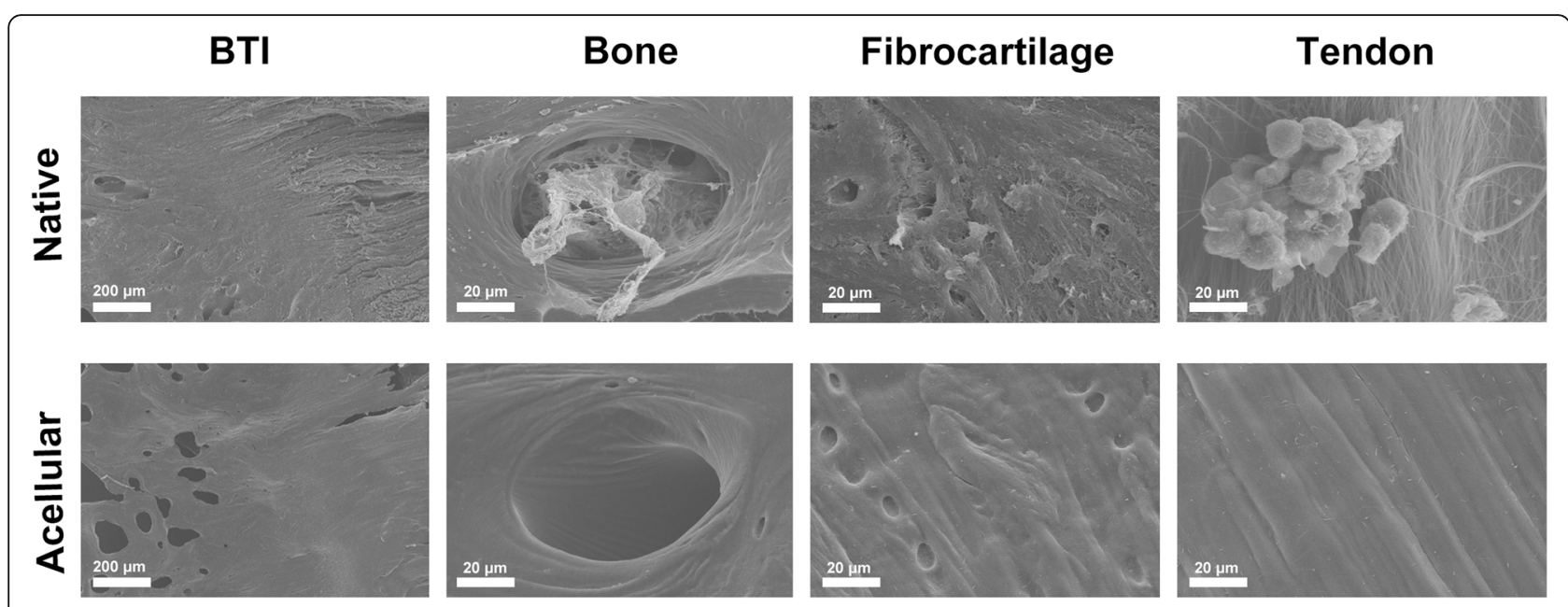

Fig. 3 From the SEM image, the decellularized book-shaped enthesis scaffolds following Su M et al' protocol preserved native collagen structure well, and no cells debris was visualized

DEM samples (Fig. 4d). Meanwhile, SR-FTIR analysis indicated that the PGs distribution at DEM was partly reserved after decellularization, its content decreased about $44.55,56.76,58.13$ and $46.33 \%$ in the bone, CF, UCF and tendon regions of NET, respectively (Fig. 4e).

\section{DNA residence and mechanical test}

After decellularization, the content of DNA was greatly reduced $(0.089 \pm 0.018 \mu \mathrm{g} / \mathrm{mg})$ in the DEM, which was significantly lower than that in the NET $(0.976 \pm$ $0.026 \mu \mathrm{g} / \mathrm{mg}) \quad(P<0.05) \quad$ (Fig. 5a). After mechanical

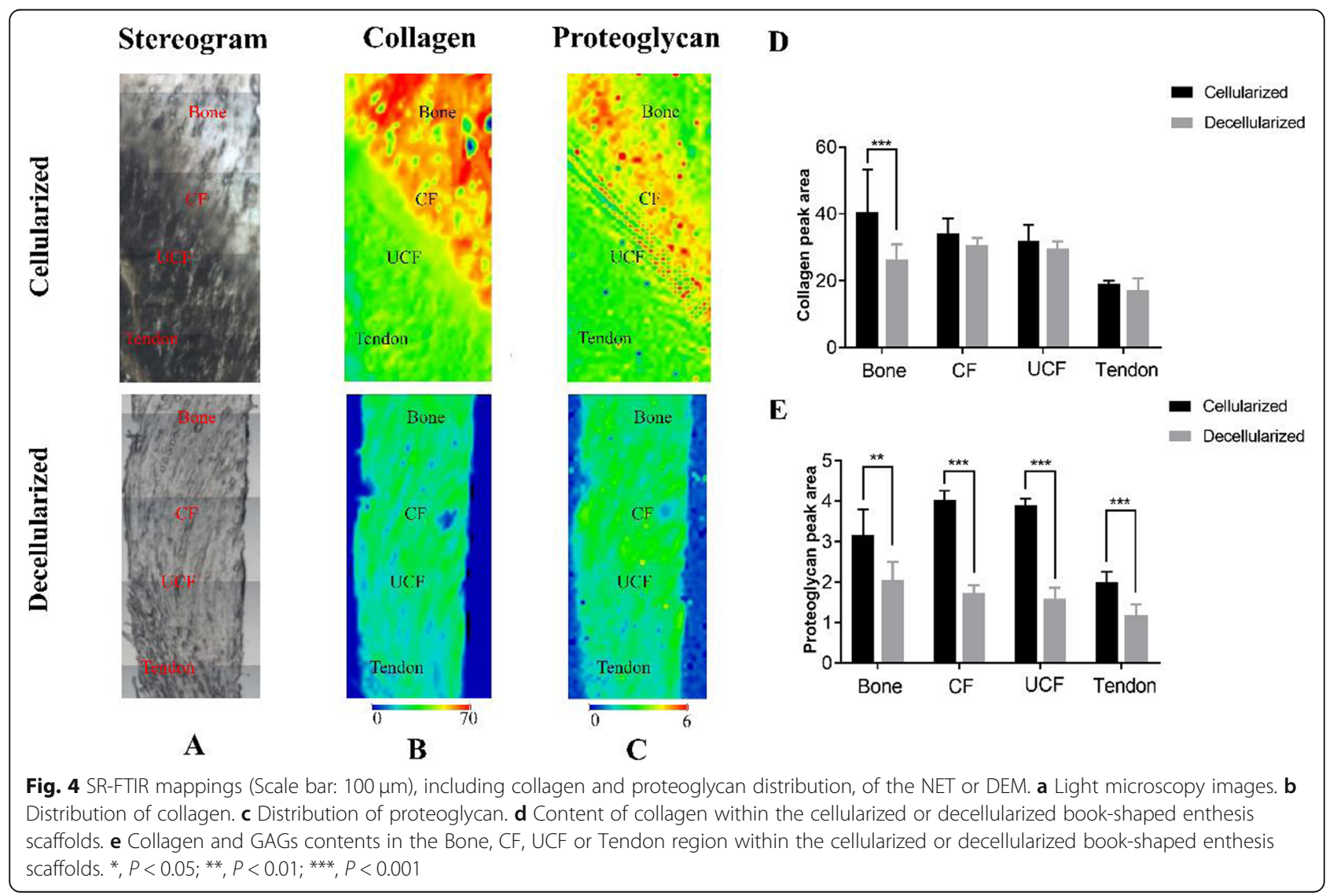




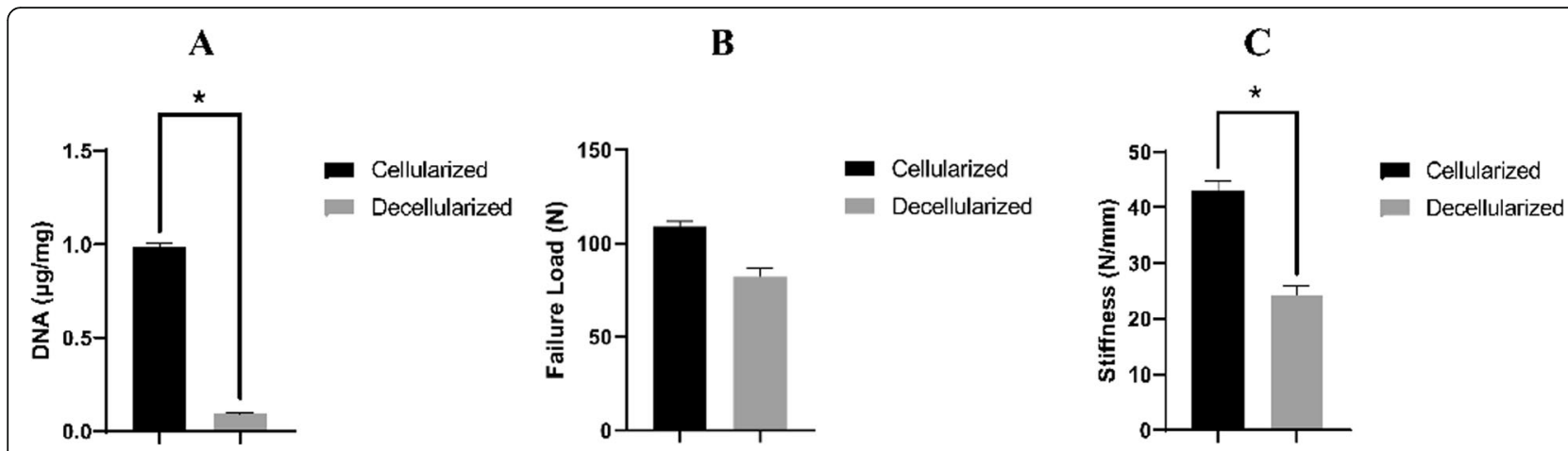

Fig. 5 Quantification of DNA, failure load, and stiffness in the decellularized book-shaped enthesis scaffolds. a Content of DNA within the NET or DEM. b The mechanical properties (failure load). c The mechanical properties (stiffness). Dissimilar letters indicating a significant difference $(P<0.05)$

testing, the failure load in the NET group showed significantly higher than that in the DEM group $(P<0.05)$ (Fig. 5b). Meanwhile, the stiffness of the DEM group was significantly lower than the NET group (Fig. 5c).

\section{Biological characteristics of DEM on BMSCs viability}

To evaluate the effects of DEM on BMSCs viability, Live/Dead assay was used to examine cell proliferation and viability of BMSCs cultured on the DEM. At day 3 after seeding, Live/Dead assay showed that most BMSCs were stained fluorescent green (living cells), with very few red (dead cells) (Fig. 6).

\section{Discussion}

The rotator cuff repair, which often leads to disability and persistent pain, is very common in the shoulder and the bone-tendon interface healing is crucial to regenerate native fibrocartilaginous structure. However, this unique tissue structure healing remains difficult because of the limited ability of tendons to self-repair [6]. To improve the healing of bone-tendon interface, tissue engineering has been widely examined in this field, utilizing a combination of scaffolds, bioactive molecules and seeded cells to repair damaged tissues.

Decellularization technology has been widely used to obtain decellularized scaffolds, such as decellularized bone, fibrocartilage, or tendon tissue. There are two crucial steps during decellularization: removing cell components and preserving the extracellular matrix components. Collagen and proteoglycan are two important biocomponents in the extracellular matrix and the main structures of bone, fibrocartilage, and tendon extracellular matrix are composed of different types of collagen [24]. In our previous study, Chen et al. applied book-shaped decellularized fibrocartilage scaffold for bone-tendon healing in patella patellar-tendon complexes and achieved better results [19]. Nevertheless, few decellularization methods, which not only well removed cell component and preserved the whole natural structure and mechanical properties, is available for the large-size enthesis scaffold. Recently, Su M et al. developed a decellularization protocol for porcine enthesis decellularization, which includes the processes of tissue-trimming, freezethaw cycles, 3\%SDS, and nuclease digestion. However, whether the contents and distribution of collagen fiber and proteoglycan could be reserved still needs to be explored.

With the development of the third generation synchrotron light source Shanghai Synchrotron Radiation Facility (SSRF), the SR-FTIR (higher spatial resolution of $5 \mu \mathrm{m}$ ) has been applied to analysis at the diffraction limit while preserving a high spectral quality [13]. The flux at

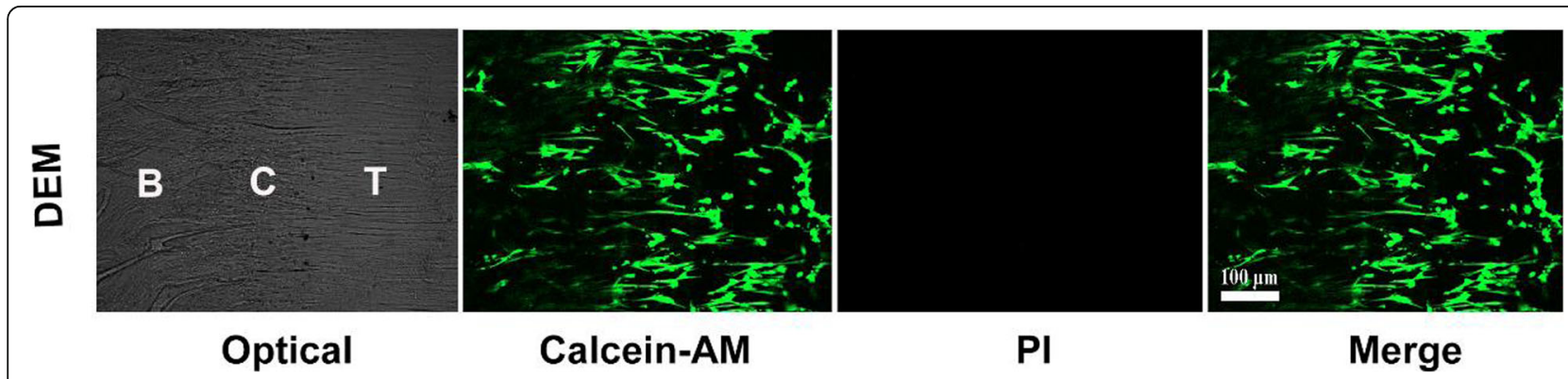

Fig. 6 Live/dead cell analysis was used to observe the cell viability of the decellularized book-shaped enthesis scaffolds. Live/dead double staining after the hBMSCs seeded on the DEM for 3 days (green fluorescence represented live cells, while red for dead). $(N=6)$. Scale bar: $100 \mu m$ 
the entrance of the SR-FTIR spectrometer has been achieved to be about $1.5 \times 10^{13}$ (photons/sec/0.1\% b.w.) at $1 \mu \mathrm{m}$ wavelength for a $230 \mathrm{~mA}$ current. These performances allow the SR-FTIR to analyse large samples with heterogeneous regions in a small area with a diffraction limited spatial resolution [25]. This study utilizes SRFTIR as it is a high-throughput and sensitive imaging modality which is capable of quantitative mapping of the content and distribution of extracellular matrix, thereby making it well suited for examining multi-tissue regions. Unlike those of traditional histological staining techniques and biochemical assays, the SR-FTIR technique can be used to quantitatively map decellularized book-shaped enthesis scaffolds. Compared with the conventional FTIR, the SR-FTIR can detect the changes in microstructure in high resolution, and determine the various components.

Meanwhile, utilizing SR-FTIR technique, both collagen, proteoglycan, as well as collagen orientation, were detected and quantified across the different regions of the decellularized book-shaped enthesis scaffolds. The extent of decellularization on extracellular matrix of the bonetendon scaffolds can be assessed by such structural chemical information. Evaluating these compositional changes is crucial to elucidating the role of the bioscaffolds in rabbit rotator cuff [15]. In this study, SR-FTIR was applied for quantitative mapping of the content and distribution of extracellular matrix in the decellularized book-shaped enthesis scaffolds from rabbit rotator cuff for the first time. As shown in our results, $40.85 \%$ collagen and $44.55 \%$ proteoglycan is lost after decellularization. Our findings provide critical information for the regeneration of bone-tendon interface and new insights into matrix composition and organization across the decellularized bone- tendon scaffold. To prove this interpretation, we should increase the number of samples and study other types of BTI in follow-up experiments.

This present study focused on quantitative mapping of changes in matrix components across the decellularized large-size enthesis tissue as scaffolds using the SR-FTIR technology. Assessing the matrix components of decellularized meniscus and cartilage extracellular matrix by the SR-FTIR technology are the next steps in the following studies. The future application of SR-FTIR would be extended to observe mineral distributions and potentially facilitate the understanding of the transition of complex loads from bone to ligament. However, there were still a few limitations that remained in the current study. Firstly, there are some differences in the biomechanics and size of the repair region between rabbits and humans. Preclinical animals such as canine or goat should be performed in the next step before clinical usage. Furthermore, comparison studies between FTIR and SR-FTIR in assessing matrix components of decellularized book-shaped enthesis scaffolds still needed further investigation.

\section{Conclusion}

In summary, the goal of this study is to utilize SR-FTIR to analyze the distributions of collagen and PGs content in the decellularized book-shaped enthesis scaffolds from rabbit rotator cuff. After following Su M et al' decellularization protocol, cell components were effectively removed and the microstructure of the scaffold was well preserved, however, changes in extracellular matrix components, such as collagen and proteoglycan, were observed.

\section{Abbreviations}

BMSC: Bone marrow stromal cell; OCT: Optimum cutting temperature; SEM: Scanning electron microscopy; SR-FTIR: Synchrotron radiation-based Fourier transform infrared microspectroscopy; SSRF: Shanghai Synchrotron Radiation Facility; NET: Native enthesis tissues; DEM: Decellularized enthesis matrix; BTI: Bone-tendon interface

\section{Acknowledgments}

We thank all the staff from BL01B beamline of National Center for Protein Science Shanghai (NCPSS) for assistance during data collection.

\section{Authors' contributions}

$\mathrm{HL}$ and $\mathrm{JH}$ conceived and designed the study. QS and CC completed the experiments. $Y C, Y X$, and $M L$ analyzed the data. JL wrote and revised the paper. The author(s) read and approved the final manuscript.

\section{Funding}

This study was supported by: (1) The Fundamental Research Funds for the Central Universities of Central South University (grant numbers 2019zzts900) (2) The National Natural Science Foundation of China (grant numbers 81730068).

\section{Availability of data and materials}

The datasets used and/or analysed during the current study are available from the corresponding author on reasonable request.

\section{Declarations}

Ethics approval and consent to participate

The Ethics Committee of Xiangya Hospital, Central South University approved the research proposal (IRB: 2019030517). All experimental procedures conformed to the guidelines in the Guide for the Care and Use of Laboratory Animals published by the Chinese National Health.

\section{Consent for publication}

Not applicable.

\section{Competing interests}

The authors declare that they have no competing interests.
Author details
${ }^{1}$ Department of Sports Medicine, Xiangya Hospital, Central South University, Changsha 410008, Hunan, China. ${ }^{2}$ Key Laboratory of Organ Injury, Aging and Regenerative Medicine of Hunan Province, Changsha 410008, Hunan, China. ${ }^{3}$ Xiangya Hospital-International Chinese Musculoskeletal Research Society Sports Medicine Research Centre, Changsha 410008, Hunan, China.
${ }^{4}$ Department of Orthopedics, Xiangya Hospital, Central South University, Changsha 410008, Hunan, China. ${ }^{5}$ Department of Spine Surgery, Xiangya Hospital, Central South University, Changsha 410008, Hunan, China.
${ }^{6}$ Department of limbs (foot and hand) microsurgery, Affiliated Chenzhou No.1 People's Hospital, Southern Medical University, Chenzhou 423000, Hunan, China. 
Received: 1 June 2020 Accepted: 22 February 2021

Published online: 01 March 2021

\section{References}

1. Atesok K, Fu FH, Wolf MR, Ochi M, Jazrawi LM, Doral MN, Lubowitz JH, Rodeo SA. Augmentation of tendon-to-bone healing. J Bone Joint Surg Am. 2014;96(6):513-21.

2. Derwin KA, Galatz LM, Ratcliffe A, Thomopoulos S. Enthesis repair: challenges and opportunities for effective tendon-to-bone healing. J Bone Joint Surg Am. 2018;100(16):e109.

3. $\mathrm{Lu} \mathrm{HH}$, Thomopoulos S. Functional attachment of soft tissues to bone: development, healing, and tissue engineering. Annu Rev Biomed Eng. 2013; 15:201-26.

4. Lu H, Chen C, Qu J, Chen H, Chen Y, Zheng C, Wang Z, Xu D, Zhou J, Zhang $\mathrm{T}$, et al. Initiation timing of low-intensity pulsed ultrasound stimulation for tendon-bone healing in a rabbit model. Am J Sports Med. 2016:44(10):2706-15.

5. Zelzer E, Blitz E, Killian ML, Thomopoulos S. Tendon-to-bone attachment: from development to maturity. Birth Defects Res C Embryo Today. 2014; 102(1):101-12

6. Benjamin M, Toumi H, Ralphs JR, Bydder G, Best TM, Milz S. Where tendons and ligaments meet bone: attachment sites ('entheses') in relation to exercise and/or mechanical load. J Anat. 2006;208(4):471-90.

7. Hu J, Qu J, Xu D, Zhang T, Qin L, Lu H. Combined application of lowintensity pulsed ultrasound and functional electrical stimulation accelerates bone-tendon junction healing in a rabbit model. J Orthop Res. 2014;32(2): 204-9.

8. Xu D, Zhang T, Qu J, Hu J, Lu H. Enhanced patella-patellar tendon healing using combined magnetic fields in a rabbit model. Am J Sports Med. 2014; 42(10):2495-501.

9. Galatz LM, Ball CM, Teefey SA, Middleton WD, Yamaguchi K. The outcome and repair integrity of completely arthroscopically repaired large and massive rotator cuff tears. J Bone Joint Surg Am. 2004;86(2):219-24.

10. Wang L, Johnson JA, Zhang Q, Beahm EK. Combining decellularized human adipose tissue extracellular matrix and adipose-derived stem cells for adipose tissue engineering. Acta Biomater. 2013;9(11):8921-31.

11. Han TT, Toutounji S, Amsden BG, Flynn LE. Adipose-derived stromal cells mediate in vivo adipogenesis, angiogenesis and inflammation in decellularized adipose tissue bioscaffolds. Biomaterials. 2015;72:125-37.

12. Guo L, Qu J, Zheng C, Cao Y, Zhang T, Lu H, Hu J. Preparation and characterization of a novel Decellularized fibrocartilage "book" scaffold for use in tissue engineering. PLoS One. 2015;10(12):e0144240.

13. Khanarian NT, Boushell MK, Spalazzi JP, Pleshko N, Boskey AL, Lu HH. FTIR-I compositional mapping of the cartilage-to-bone interface as a function of tissue region and age. J Bone Miner Res. 2014;29(12):2643-52.

14. Zabrzyński J, Łapaj Ł, Paczesny Ł, Zabrzyńska A, Grzanka D. Tendon function-related structure, simple healing process and mysterious ageing. Folia Morphol (Warsz). 2018;77(3):416-27.

15. Spalazzi JP, Boskey AL, Pleshko N, Lu HH. Quantitative mapping of matrix content and distribution across the ligament-to-bone insertion. PLoS One. 2013;8(9):e74349.

16. Wopenka B, Kent A, Pasteris JD, Yoon Y, Thomopoulos S. The tendon-tobone transition of the rotator cuff: a preliminary Raman spectroscopic study documenting the gradual mineralization across the insertion in rat tissue samples. Appl Spectrosc. 2008;62(12):1285-94.

17. Schwartz AG, Pasteris JD, Genin GM, Daulton TL, Thomopoulos S. Mineral distributions at the developing tendon enthesis. PLoS One. 2012;7(11): e48630.

18. Kastyak-Ibrahim MZ, Nasse MJ, Rak M, Hirschmugl C, Del Bigio MR, Albensi BC, Gough KM. Biochemical label-free tissue imaging with subcellularresolution synchrotron FTIR with focal plane array detector. Neuroimage. 2012;60(1):376-83

19. Chen C, Liu F, Tang Y, Qu J, Cao Y, Zheng C, Chen Y, Li M, Zhao C, Sun L, et al. Book-shaped Acellular fibrocartilage scaffold with cell-loading capability and Chondrogenic Inducibility for tissue-engineered fibrocartilage and bone-tendon healing. ACS Appl Mater Interfaces. 2019;11(3):2891-907.

20. Zhou Y, Chen C, Guo Z, Xie S, Hu J, Lu H. SR-FTIR as a tool for quantitative mapping of the content and distribution of extracellular matrix in decellularized book-shape bioscaffolds. BMC Musculoskelet Disord. 2018; 19(1):220.
21. Adams JE, Zobitz ME, Reach JS Jr, An KN, Steinmann SP. Rotator cuff repai using an acellular dermal matrix graft: an in vivo study in a canine model. Arthroscopy. 2006;22(7):700-9.

22. Mathewson MA, Kwan A, Eng CM, Lieber RL, Ward SR. Comparison of rotator cuff muscle architecture between humans and other selected vertebrate species. J Exp Biol. 2014;217(Pt 2):261-73.

23. Su M, Zhang Q, Zhu Y, Wang S, Lv J, Sun J, Qiu P, Fan S, Jin K, Chen L et al. Preparation of Decellularized Triphasic Hierarchical Bone-FibrocartilageTendon Composite Extracellular Matrix for Enthesis Regeneration. Adv Healthc Mater. 2019;8(19):e1900831.

24. Calejo I, Costa-Almeida R, Gomes ME. Cellular complexity at the Interface: challenges in Enthesis tissue engineering. Adv Exp Med Biol. 2019;1144:71-90.

25. Zhang ZY, Chen M, Tong YJ, Ji T, Zhu HC, Peng WW, Zhang M, Li YJ, Xiao TQ. Performance of the infrared microspectroscopy station at SSRF. Infrared Phys Technol. 2014;67:521-5.

\section{Publisher's Note}

Springer Nature remains neutral with regard to jurisdictional claims in published maps and institutional affiliations.
Ready to submit your research? Choose BMC and benefit from:

- fast, convenient online submission

- thorough peer review by experienced researchers in your field

- rapid publication on acceptance

- support for research data, including large and complex data types

- gold Open Access which fosters wider collaboration and increased citations

- maximum visibility for your research: over $100 \mathrm{M}$ website views per year

At BMC, research is always in progress.

Learn more biomedcentral.com/submissions 